\title{
Comment
}

\section{OR in developing countries}

\section{SUBHASH DATTA}

After attending several OR conferences in India and the 1987 UK National Conference in Edinburgh, I was seriously thinking about the future of $O R$ in general and in the developing countries in particular. Where are we going? What role should or could OR play in the future? The way things are moving, will there be any OR by 2000 $A D$ ?

If the current thinking and trends continue, $O R$ will be nothing but applied common sense. Soft OR, artificial intelligence and decision support systems are the likely areas where OR professionals will be working, with some work on 'community OR'. This trend is sure to be damaging to the profession of OR. The money on sponsored studies will obviously rush towards 'action research'. Less and less will be devoted to idea generation or to generating alternatives to solve the complex and messy problems. The 'best' research work will be on those areas which are 'possible' but may not necessarily be 'desirable'. The search for 'possible' answers instead of 'desirable' (and difficult) solutions will breed mediocrity in OR professionals. Moreover, the increasing trend in using computer software in problemsolving will lead to the search for 'packages' which can solve most of the problems. In the process we will try to fit a package to a problem, rather than try to understand, innovate, formulate and solve the problem. It is so convenient. The LP package may give some idea of the use of LP in the past. 'Soft OR' and 'software' will be key words for the operational researcher.

The scene in the developing countries will become much worse. First of all, we do not yet clearly know what is meant by OR in developing countries. Is it any OR model used in a developing country? Consider, for example, a multinational company situated in, say, India using an inventory model or a production planning model. Is this OR in a developing country? Many such applications of OR in the literature (particularly in the special issues on developing countries) are responsible for such misconceptions.

It has also been found that a glamorous paper using a sophisticated mathematical model but divorced from the reality is more likely to be accepted in international journals than a non-glamorous paper (application) dealing with the relevant issues and complex problems of a developing country. But who decides what is 'relevant' OR in a developing country?

The recognized expertise in developing countries seems to be inversely proportional to the time spent by the expert in a developing country. The place of residence of the 'expert' should preferably be in a developed country.

All these issues are interlinked and are very important for determining the future of $\mathrm{OR}$ in the developing countries.

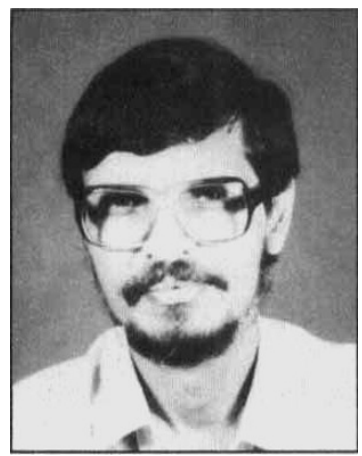

SUBHASH DATTA is an Assistant Professor at the Centre for Applied Systems Analysis in Development (CASAD), D5/8 Salunke Vihar, Pune-411022, India. He is also an executive council member of the Operational Research Society of India. 